\title{
A parental educational intervention to facilitate informed consent for pediatric procedural sedation in the emergency department: a parallel group randomized controlled trial
}

\author{
Yen-Ko Lin \\ Kaohsiung Medical University Chung Ho Memorial Hospital \\ Yung-Sung Yeh \\ Kaohsiung Medical University Chung Ho Memorial Hospital \\ Chao-Wen Chen \\ Kaohsiung Medical University Chung Ho Memorial Hospital \\ Wei-Che Lee \\ Kaohsiung Medical University Chung Ho Memorial Hospital \\ Chia-Ju Lin ( $\square$ chiaju@kmu.edu.tw ) \\ Liang-Chi Kuo \\ Kaohsiung Medical University Chung Ho Memorial Hospital \\ Leiyu Shi \\ Johns Hopkins University Bloomberg School of Public Health
}

\section{Research article}

Keywords: Informed Consent, Pediatric Procedural Sedation, Knowledge, Satisfaction, Emergency Department

Posted Date: May 19th, 2020

DOI: https://doi.org/10.21203/rs.3.rs-27624/v1

License: (c) (i) This work is licensed under a Creative Commons Attribution 4.0 International License. Read Full License 


\section{Abstract \\ Background}

Obtaining valid parental informed consent for pediatric procedures in the emergency department (ED) is challenging. This study compared a video-assisted informed consent intervention with conventional consent discussion to inform parents about pediatric procedural sedation in the ED.

\section{Methods}

A video-assisted informed consent intervention was developed to explain the process, benefits, risks, and alternatives of pediatric procedural sedation. A prospective randomized controlled trial was conducted with a convenience sample of parents of children recommended for procedural sedation for facial laceration in the ED. Intervention group participants watched the video. Control group participants received information from physicians during conventional discussion. Participants completed pre- and post-education knowledge tests and rated their satisfaction with the informed consent process. The primary outcome was efficacy of the video intervention compared with conventional discussion. Secondary outcomes were parental satisfaction and consent refusal. A covariate-controlled multivariable regression model was used to analyze between-group differences in knowledge and satisfaction.

\section{Results}

There were 32 participants in the intervention group and 30 in the control group. Mean knowledge scores were higher in the intervention group (91.67 \pm [standard deviation] 12.70) than in the control group (73.33 \pm 19.86$)$. The intervention group showed significantly greater knowledge score differences (coefficient: 18.931, 95\% confidence interval: 11.14626.716). Intervention group participants showed greater satisfaction than control group participants.

\section{Conclusions}

Video-assisted informed consent was superior to conventional discussion for informing parents during an ED informed consent process. Video-assisted informed consent may improve parents' understanding of pediatric procedural sedation and satisfaction with the informed consent process in the ED. Institutions should develop structured methods and strategies to better inform parents, facilitate treatment decisions, and improve parent satisfaction in the ED.

\section{Trial registration:}

The ClinicalTrials.gov Identifier is NCT01850329. Registered 9 May, 2013 - Retrospectively registered, https://www.clinicaltrials.gov/ct2/show/study/NCT01850329

\section{Background}

For ethical and legal reasons, it is crucial that physicians provide patients with information about procedures, risks, benefits, and treatment alternatives during the informed consent process.[1-3] Obtaining informed consent is a process, not merely a matter of documentation.[4-9] Patients must understand the relevant information to provide their informed consent to medical procedures. A full understanding of such information helps patients to make individual choices.[1013] 
Obtaining valid informed consent from patients in the emergency department (ED) is a challenging and time-consuming process. Providing parents or surrogates with adequate education prior to emergency procedures on children can be particularly challenging. In emergency settings, time constraints and stress (as well as distress caused by pain or other acute symptoms) often make it difficult for patients and their families to grasp the information needed to provide consent.[14-18] Therefore, physicians must make a particular effort to communicate information to patients and family members to help them to make rational decisions even under these most demanding conditions.

Procedural sedation is the use of sedative, analgesic, and dissociative drugs to produce analgesia, sedation, and motor control during uncomfortable or painful diagnostic and therapeutic procedures.[19] It is an ethical imperative to provide children with relief from pain and anxiety associated with diagnostic and therapeutic procedures; from the parents' perspective, such relief is also an indicator of quality of care. $[19,20]$ In the ED, many children present with acute conditions and procedural sedation is recommended. Though the safety profile of the procedure has improved, patients are still exposed to significant risks from potentially severe adverse events.[19-25] Reported rates of adverse events range from $0.6-17 \%$ and include airway complications (e.g., partial airway obstruction, respiratory depression, apnea, laryngospasm), emesis, and recovery agitation (defined as any combination of agitation, crying, hallucinations, or nightmares).

Research shows that during the traditional consent process, trauma patients and their families have difficulty retaining the substantial amount of information presented to them; at the same time, they are often unable to imagine how the procedure or surgery will proceed. Therefore, it may be practical to use an educational video to assist the informed consent process for procedural sedation. Several studies indicate that patient educational videos generate better patient satisfaction and improved patient knowledge of procedures and risks.[26-30] There may be both an ethical and practical need for a video-assisted intervention to facilitate informed consent for pediatric procedural sedation. This study therefore explored the use of an educational intervention to improve the informed consent process. Clinical studies in other medical areas have shown that interventions to educate patients and their families help them to retain more information. However, to the best of our knowledge, the use of video-assisted informed consent before pediatric procedural sedation in the ED has never been studied.

The study aim was to develop a video-assisted informed consent intervention tool and to determine whether videoassisted informed consent was superior to routine discussion for informing parents in the ED about risks, benefits, and alternatives to procedural sedation for their children.

\section{Methods}

\section{Intervention tool}

A video and knowledge test questionnaire were developed. At the study start, a panel of experts used the literature and best practice guidelines to develop the knowledge test questionnaire and video contents. The experts met regularly and reached consensus on the study materials. The video was contracted and produced by a multimedia company. The final script contained information about the sedation procedure, risks, benefits, and alternatives. The video describing the procedure was developed using advanced two-dimensional graphics technology and role-playing by actors. An audio narrative described the video contents and written subtitles and captions were added. The video included several sections: "Introduction," "Purpose and Benefits of the Procedure," "Preparation and Monitoring," "the Procedure," "Complications and Risks," and "Questions and Answers." Treatment alternatives were included in the "Questions and Answers" section. 
A portable computer preloaded with the information program was used. The volume was adjusted to ensure that participants could hear the narrative. A research associate was present during the participant's navigation through the process to ensure completion and help as needed. Completion of the video took approximately 6 minutes, after which participants could ask a physician questions about the procedure.

A questionnaire assessing knowledge of the purpose, benefits, and risks of procedural sedation was compiled based on previous questionnaires.[19-25] This questionnaire also recorded the following participant demographic data, including age, sex, and level of education. The experts revised the questionnaire after a pilot test to produce a final version (see Additional File 1).

\section{Study design}

A prospective randomized controlled trial using a superiority design was conducted during the second stage of the study in the ED of a tertiary university hospital. Participants were parents of children recommended for procedural sedation for facial laceration. Ketamine (4-5 mg/kg, intramuscular) was provided for pediatric procedural sedation. Participants randomized to the intervention group received the video-assisted informed consent intervention, which explained the procedure and its risks, benefits, and alternatives. The control group participated in routine discussion with a physician, who provided information about the procedure. All participants completed the knowledge questionnaire before and after the educational sessions. The questionnaire also included three questions to assess satisfaction with the informed consent process on a 5-point Likert scale. The study protocol was reviewed and approved by the institutional review board of the hospital before the study began. Participants provided written informed consent before enrollment.

\section{Participant Selection}

All parents with patients older than 1 year and younger than 7 years of age who had been recommended for procedural sedation for facial laceration were eligible for enrollment, if a trained research associate was available. Exclusion criteria included parental refusal to participate, inability to understand the study process, patient clinical instability, or inability to speak and read Mandarin. If an eligible participant was missed, the reason was recorded in a study logbook.

The following power assumptions were made: (a) education will increase the mean questionnaire score (postknowledge scores will be higher; mean difference $16 \%$ for control group and $32 \%$ for intervention group); (b) scores will be normally distributed; (c) standard deviation = 16 for both groups; (d) a level of significance of 0.05 ( $p<0.05)$; (e) twotailed $t$-test; (f) a $20 \%$ dropout rate used to analyze the data. Given these assumptions, it was determined that a sample size of 29 in each group was needed to achieve an effect size more than 0.8 with $90 \%$ power and a significance of 0.05 .

\section{Data Collection and Processing}

A prescript approach was used for eligible participants to process the study and written informed consent was obtained. Using simple randomization based on odd or even numbers generated from a computer-based random number generator, participants were assigned randomly to either the control or the intervention group. The allocation procedure was concealed. After randomization, a research associate collected demographic information (age, sex, and selfreported education level). Other data, including ED arrival time and emergency physician, were collected from patient charts and the hospital computer system.

All participants completed the multiple-choice knowledge test before the educational sessions. Control group participants received information about the procedure from their physician through conventional discussion. Following the discussion, participants completed the knowledge test and questions evaluating their satisfaction with the informed consent process. Intervention group participants obtained information from the video on a laptop at the patient's bedside. Participants were able to pause and/or replay the video intervention. If participants had additional questions 
about the procedure, they were able to speak with the physician after the educational session. The aim of this questionand-answer session was to provide a similar opportunity for questions as provided in the control group conventional informed consent process. Participants in both groups completed the same knowledge test and satisfaction measures after the question-and-answer session.

In our ED, emergency attending physicians are responsible for obtaining informed consent for the procedure. Physicians obtaining informed consent were blinded to the knowledge questions and the research associate who assessed the outcomes was blinded to the interventions.

\section{Outcome Measures}

The primary outcome was the knowledge test to evaluate participant understanding of pediatric procedural sedation. Questions were multiple-choice and equally weighted. Total scores were out of 6 , and were converted to a percentage (total possible knowledge score range: $0-100 \%$ ).

The secondary outcomes were participant satisfaction with the informed consent process (rated on a 5-point ordinal Likert scale) and the frequency of consent refusal.

\section{Data Analysis}

To ensure participant confidentiality, data were recorded by participant number with no specific identification. Collected data included participant demographics, ED arrival time, and the names of treating physicians. Descriptive statistics were calculated for the demographic characteristics of the control and intervention groups. Continuous variables were analyzed using mean and standard deviation, and proportions were calculated for categorical variables. Fisher's exact test was used for binary, ordinal, and categorical variables. Mean pre- and post-education scores on the knowledge questionnaire were compared using Student's $t$-test between each group and the paired $t$-test within each group.

Differences in knowledge scores were calculated by subtracting pre-education scores from post-education scores. Independent factors were entered into multivariable regression models if they were associated with differences in knowledge and satisfaction in a univariate analysis, or if they were clinically important. A multiple linear regression model, a linear regression model with backward elimination, and a multiple ordinal logistic regression model for knowledge score differences with predefined covariates were used. A multivariable ordinal logistic regression model of parent satisfaction, with predefined covariates, was used together with likelihood ratio tests for the multivariable models. A threshold of $p<0.05$ was used to indicate statistical significance and $95 \%$ confidence intervals were computed. All analyses were conducted using Stata version 14.0 (StataCorp LP, College Station, TX, USA).

\section{Results}

A total of 118 children received the procedure during the one-year study period (Fig. 1). Forty-five participants were not enrolled as a research associate was unavailable. Four parents unable to understand the study process and seven who refused to participate were excluded. Data are thus presented for 62 participants (Additional File 2: Appendix 2); 32 were assigned to the video intervention group and 30 to the control group. There were no notable differences in baseline characteristics between the control and intervention groups.

\section{Knowledge measure}

Table 1 summarizes the main outcomes for all study participants. There was no significant difference in baseline knowledge scores between the intervention and control groups. Knowledge scores were higher after education than at baseline in both groups, but participants in the intervention group had greater post-education understanding than those 
in the control group (mean knowledge scores 91.67 versus 73.33, respectively). The intervention group showed a greater improvement in knowledge scores after the educational session (mean knowledge score difference 36.98) than the control group (mean knowledge score difference 20.00). We also categorized knowledge score differences as $\leq 20,21-$ 49 , and $\geq 50$. There were significant between-group differences in scores in these categories (Table 1).

Table 1

Baseline and post-education knowledge scores

\begin{tabular}{|c|c|c|c|c|c|}
\hline \multirow[t]{2}{*}{ Knowledge score } & \multicolumn{2}{|c|}{ Control $(n=30)$} & \multicolumn{2}{|c|}{ Intervention ( $n=32)$} & \multirow[t]{2}{*}{$p$-value ${ }^{\mathrm{d}}$} \\
\hline & Mean & Standard Deviation & Mean & Standard Deviation & \\
\hline Baseline & 52.78 & 19.61 & 54.69 & 16.52 & 0.679 \\
\hline Post-education & 73.33 & 19.86 & 91.67 & 12.70 & $<0.001$ \\
\hline \multirow[t]{2}{*}{${ }^{\mathrm{c} D i f f e r e n c e}$} & 20.00 & 14.11 & 36.98 & 20.62 & $<0.001^{\mathrm{a}}$ \\
\hline & \multicolumn{2}{|c|}{ Number (\%) } & \multicolumn{2}{|c|}{ Number (\%) } & \\
\hline$\leqq 20$ & \multicolumn{2}{|c|}{$20(66.67)$} & \multicolumn{2}{|c|}{$9(28.13)$} & $0.002^{\mathrm{b}}$ \\
\hline $21 \sim 49$ & \multicolumn{2}{|c|}{$8(26.67)$} & \multicolumn{2}{|c|}{$10(31.25)$} & \\
\hline$\geq 50$ & \multicolumn{2}{|c|}{$2(6.67)$} & \multicolumn{2}{|c|}{$13(40.63)$} & \\
\hline \multicolumn{5}{|c|}{ a Unequal variance test } & \\
\hline \multicolumn{5}{|l|}{ b Fisher's exact test } & \\
\hline \multicolumn{6}{|c|}{${ }^{\mathrm{c}}$ Difference $=$ (Post-education knowledge score) - (Baseline knowledge score) } \\
\hline \multicolumn{5}{|c|}{${ }^{d}$ Intervention vs Control } & \\
\hline
\end{tabular}

There was no significant difference between the control and intervention subgroups in baseline knowledge scores (Additional File 3: Appendix 3). Post-education knowledge scores for the control and intervention subgroups were compared and scores were significantly greater for some intervention subgroups (Additional File 4: Appendix 4). These included being female, arrival time other than 08:00-16:00 h, and physicians B and C. Regardless of age $(<34$ or $\geq$ 34 years) and education level (< college or $\geq$ college), intervention group participants had significantly higher posteducation knowledge scores.

Table 2 shows subgroup differences in knowledge scores. Differences in knowledge scores were significantly greater in the intervention group than in the control group for the subgroups of age $<34$ years, being female, education level equal to and above college, arrival time other than 08:00-16:00 h, and physicians B and C. The educational video may have had a greater impact on participants in those subgroups because they showed greater differences between baseline and post-education knowledge scores. 
Table 2

The difference of knowledge scores compared between control and intervention subgroups.

\begin{tabular}{|c|c|c|c|c|c|c|c|c|}
\hline \multirow{2}{*}{$\begin{array}{l}\text { Analysis } \\
\text { variable }\end{array}$} & \multicolumn{3}{|c|}{ Control } & \multicolumn{3}{|c|}{ Intervention } & \multirow{2}{*}{$\begin{array}{l}p- \\
\text { value }\end{array}$} & \multirow{2}{*}{$\begin{array}{l}\text { p-value for interaction of } \\
\text { experimental group and analysis } \\
\text { variable }\end{array}$} \\
\hline & $\mathrm{n}$ & Mean & $\begin{array}{l}\text { Standard } \\
\text { deviation }\end{array}$ & $\mathrm{n}$ & Mean & $\begin{array}{l}\text { Standard } \\
\text { deviation }\end{array}$ & & \\
\hline \multicolumn{9}{|l|}{$\begin{array}{l}\text { Age } \\
\text { (years) }\end{array}$} \\
\hline$<34$ & 16 & 18.75 & 11.98 & 17 & 41.18 & 18.74 & $\begin{array}{l}< \\
0.001^{\mathrm{a}}\end{array}$ & 0.203 \\
\hline$\geq 34$ & 14 & 21.43 & 16.57 & 15 & 32.22 & 22.24 & $0.149^{a}$ & \\
\hline \multicolumn{9}{|l|}{ Sex } \\
\hline Female & 23 & 18.84 & 13.58 & 24 & 40.28 & 18.98 & $\begin{array}{l}< \\
0.001^{\mathrm{a}}\end{array}$ & 0.086 \\
\hline Male & 7 & 23.81 & 16.26 & 8 & 27.08 & 23.46 & $0.757^{a}$ & \\
\hline \multicolumn{9}{|l|}{ Education } \\
\hline$<$ College & 13 & 25.64 & 16.12 & 12 & 40.28 & 25.09 & $0.102^{\mathrm{a}}$ & 0.611 \\
\hline$\geq$ College & 17 & 15.69 & 10.98 & 20 & 35.00 & 17.85 & $\begin{array}{l}< \\
0.001^{a}\end{array}$ & \\
\hline \multicolumn{9}{|l|}{$\begin{array}{l}\text { Arrival } \\
\text { time }\end{array}$} \\
\hline $\begin{array}{l}\text { 08:00- } \\
16: 00 \mathrm{~h}\end{array}$ & 12 & 20.83 & 10.36 & 9 & 31.48 & 22.74 & $0.219^{a}$ & 0.355 \\
\hline Others & 18 & 19.45 & 16.42 & 23 & 39.13 & 19.85 & $0.001^{a}$ & \\
\hline \multicolumn{9}{|l|}{ Physician } \\
\hline $\begin{array}{l}\text { Physician } \\
\text { A }\end{array}$ & 4 & 12.50 & 8.34 & 5 & 33.33 & 20.41 & $0.087^{a}$ & 0.464 \\
\hline $\begin{array}{l}\text { Physician } \\
\text { B }\end{array}$ & 5 & 23.33 & 9.13 & 4 & 37.50 & 8.33 & $0.047^{a}$ & \\
\hline $\begin{array}{l}\text { Physician } \\
\text { C }\end{array}$ & 4 & 12.50 & 15.96 & 8 & 43.75 & 21.71 & $0.022^{a}$ & \\
\hline $\begin{array}{l}\text { Physician } \\
\text { D }\end{array}$ & 7 & 21.43 & 18.54 & 6 & 30.56 & 19.48 & $0.409^{a}$ & \\
\hline $\begin{array}{l}\text { Physician } \\
\text { E }\end{array}$ & 5 & 26.67 & 19.00 & 6 & 30.56 & 24.53 & $0.774^{\mathrm{a}}$ & \\
\hline $\begin{array}{l}\text { Physician } \\
\text { F }\end{array}$ & 5 & 20.00 & 7.45 & 3 & 50.00 & 28.87 & $0.210^{\mathrm{a}}$ & \\
\hline
\end{tabular}


Table 3 shows the analysis results of knowledge score differences using the simple regression model, multiple linear regression model, linear regression model with backward elimination, and multiple ordinal logistic regression model. A multiple linear regression model was used to examine the adjusted impact of video education, controlling for predefined covariates. The results showed that video education significantly increased the differences in knowledge scores; the average difference in knowledge score increased by 18.931 points. Baseline knowledge score also significantly affected the differences in knowledge scores (coefficient: -0.766); lower baseline knowledge score was correlated with greater knowledge score differences. The coefficients remained similar in the linear regression model with backward elimination. In the multiple ordinal logistic regression model, the adjusted odds ratio for the intervention group indicated that the intervention increased knowledge score differences (adjusted odds ratio for the knowledge score difference in the intervention group $=21.243$ ). 
Table 3

Differences in knowledge scores by regression models.

\begin{tabular}{|c|c|c|c|c|c|c|c|c|}
\hline & \multicolumn{2}{|c|}{$\begin{array}{l}\text { Simple linear regression } \\
\text { model }\end{array}$} & \multicolumn{2}{|c|}{$\begin{array}{l}\text { Multiple linear } \\
\text { regression } \\
\text { model }\end{array}$} & \multicolumn{2}{|c|}{$\begin{array}{l}\text { Linear regression } \\
\text { model with backward } \\
\text { elimination }\end{array}$} & \multicolumn{2}{|c|}{$\begin{array}{l}\text { Multiple ordinal logistic } \\
\text { regression model }\end{array}$} \\
\hline & Coefficient & $95 \% \mathrm{Cl}$ & Coefficient & $95 \% \mathrm{Cl}$ & Coefficient & $95 \% \mathrm{Cl}$ & $\begin{array}{l}\text { Odds } \\
\text { ratio }\end{array}$ & $95 \% \mathrm{Cl}$ \\
\hline $\begin{array}{l}\text { Intervention } \\
\text { group }\end{array}$ & 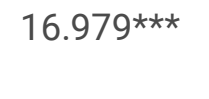 & $\begin{array}{l}7.941- \\
26.016\end{array}$ & $18.931^{\star \star \star}$ & $\begin{array}{l}11.146- \\
26.716\end{array}$ & $18.059 * * *$ & $\begin{array}{l}10.593- \\
25.525\end{array}$ & $21.243^{\star \star \star}$ & $\begin{array}{l}4.944- \\
91.269\end{array}$ \\
\hline Age & -0.568 & $\begin{array}{l}-1.492- \\
0.356\end{array}$ & 0.104 & $\begin{array}{l}-0.617- \\
0.825\end{array}$ & & & 0.998 & $\begin{array}{l}0.892- \\
1.116\end{array}$ \\
\hline $\begin{array}{l}\text { Sex } \\
\text { (reference } \\
\text { group = } \\
\text { female) }\end{array}$ & -4.231 & $\begin{array}{l}-15.902- \\
7.439\end{array}$ & -6.497 & $\begin{array}{l}-15.470- \\
2.477\end{array}$ & & & 0.556 & $\begin{array}{l}0.143- \\
2.156\end{array}$ \\
\hline $\begin{array}{l}\text { Education } \\
\text { (reference } \\
\text { group =< } \\
\text { college) }\end{array}$ & -6.540 & $\begin{array}{l}-16.633- \\
3.553\end{array}$ & 9.286 & $\begin{array}{l}-0.529- \\
19.102\end{array}$ & & & 3.229 & $\begin{array}{l}0.730- \\
14.289\end{array}$ \\
\hline $\begin{array}{l}\text { Arrival time } \\
\text { (reference } \\
\text { group = } \\
\text { others) }\end{array}$ & 5.091 & $\begin{array}{l}-5.433- \\
15.616\end{array}$ & -1.132 & $\begin{array}{l}-9.334- \\
7.070\end{array}$ & & & 0.739 & $\begin{array}{l}0.215- \\
2.533\end{array}$ \\
\hline $\begin{array}{l}\text { Physician } \\
\text { (reference } \\
\text { group = } \\
\text { physician } \\
\text { C) }\end{array}$ & -5.666 & $\begin{array}{l}-18.287- \\
6.955\end{array}$ & 4.511 & $\begin{array}{l}-5.718- \\
14.740\end{array}$ & & & 1.085 & $\begin{array}{l}0.241- \\
4.886\end{array}$ \\
\hline $\begin{array}{l}\text { Baseline } \\
\text { knowledge } \\
\text { score }\end{array}$ & 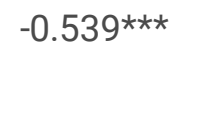 & $\begin{array}{l}-0.784- \\
0.294\end{array}$ & $-0.766^{\star \star \star}$ & $\begin{array}{l}-1.048- \\
0.483\end{array}$ & $-0.566 * \star \star$ & $\begin{array}{l}-0.775- \\
0.356\end{array}$ & $0.890 * \star \star$ & $\begin{array}{l}0.844- \\
0.938\end{array}$ \\
\hline Constant & & & 23.093 & $\begin{array}{l}-18.411- \\
64.598\end{array}$ & $49.863^{\star \star \star}$ & $\begin{array}{l}37.581- \\
62.145\end{array}$ & & \\
\hline & & & \multicolumn{2}{|l|}{$\begin{array}{l}\text { R squared = } \\
0.515\end{array}$} & \multicolumn{2}{|c|}{2 squared $=0.459$} & \multicolumn{2}{|c|}{$\begin{array}{l}\text { Likelihood ratio test } \\
\text { for model: } \chi 2= \\
44.36 ; p<0.001\end{array}$} \\
\hline \multicolumn{9}{|c|}{ 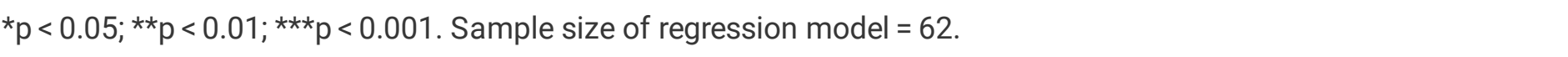 } \\
\hline Cl: confidenc & interval & & & & & & & \\
\hline
\end{tabular}


Patient satisfaction as measured on a 5-point scale was showed in Additional File 5: Appendix 5. There were statistically significant differences between the control and intervention groups on "I can comprehend the information that healthcare providers gave about the procedure," "The information that healthcare providers gave helped me make a decision about the procedure," and "I am satisfied with the informed consent process for the procedure." No participants refused to provide consent for the procedure.

Table 4 shows the multivariable ordinal logistic regression model results for parent satisfaction, controlling for the predefined covariates of age, gender, education level, arrival time, physician, and baseline knowledge score. The adjusted odds ratio for the intervention group indicated that the video improved perceptions of satisfaction. The adjusted odds ratios for "I can comprehend the information that healthcare providers gave about the procedure," "The information that healthcare providers gave helped me make a decision about the procedure," and "I am satisfied with the informed consent process for the procedure" were 4.838 (95\% confidence interval 1.606-14.575), 3.871 (95\% confidence interval 1.312-11.422), and 6.544 (95\% confidence interval 2.088-20.507), respectively. 
Table 4

Multivariable ordinal logistic regression model for satisfaction

\begin{tabular}{|c|c|c|c|c|c|c|}
\hline & \multicolumn{2}{|c|}{$\begin{array}{l}\text { I can comprehend the } \\
\text { information that healthcare } \\
\text { providers gave about the } \\
\text { procedure }\end{array}$} & \multicolumn{2}{|c|}{$\begin{array}{l}\text { The information that healthcare } \\
\text { providers gave helped me make a } \\
\text { decision about the procedure }\end{array}$} & \multicolumn{2}{|c|}{$\begin{array}{l}\text { I am satisfied with the } \\
\text { informed consent } \\
\text { process for the } \\
\text { procedure }\end{array}$} \\
\hline & Odds ratio & $95 \% \mathrm{Cl}$ & Odds ratio & $95 \% \mathrm{Cl}$ & $\begin{array}{l}\text { Odds } \\
\text { ratio }\end{array}$ & $95 \% \mathrm{Cl}$ \\
\hline \multicolumn{7}{|l|}{$\begin{array}{l}\text { (reference } \\
\text { group = } \\
\text { control } \\
\text { group) }\end{array}$} \\
\hline $\begin{array}{l}\text { Age } \\
\text { (reference } \\
\text { group }= \\
\text { age }<34 \text { ) }\end{array}$ & 0.680 & $0.236-1.955$ & 1.018 & $0.361-2.870$ & 0.622 & $\begin{array}{l}0.214- \\
1.809\end{array}$ \\
\hline $\begin{array}{l}\text { Sex } \\
\text { (reference } \\
\text { group = } \\
\text { female) }\end{array}$ & 1.134 & $0.324-3.970$ & 1.413 & $0.397-5.026$ & 0.906 & $\begin{array}{l}0.258- \\
3.184\end{array}$ \\
\hline Education & $4.278 *$ & $1.072-17.066$ & $5.178 *$ & $1.305-20.548$ & 3.405 & $\begin{array}{l}0.822- \\
14.097\end{array}$ \\
\hline \multicolumn{7}{|l|}{$\begin{array}{l}\text { (reference } \\
\text { group }=< \\
\text { college) }\end{array}$} \\
\hline $\begin{array}{l}\text { Arrived } \\
\text { time } \\
\text { (reference } \\
\text { group = } \\
\text { others) }\end{array}$ & 0.675 & $0.221-2.064$ & 0.504 & $0.167-1.526$ & 0.520 & $\begin{array}{l}0.165- \\
1.644\end{array}$ \\
\hline $\begin{array}{l}\text { Physician } \\
\text { (reference } \\
\text { group = } \\
\text { physician } \\
\text { C) }\end{array}$ & 0.917 & $0.211-3.976$ & 0.503 & $0.106-2.394$ & 0.495 & $\begin{array}{l}0.102- \\
2.402\end{array}$ \\
\hline $\begin{array}{l}\text { Baseline } \\
\text { knowledge } \\
\text { score (BKS) } \\
\text { (reference } \\
\text { group = } \\
\text { BKS <60) }\end{array}$ & 0.450 & $0.109-1.863$ & 0.318 & $0.077-1.309$ & 0.378 & $\begin{array}{l}0.088- \\
1.630\end{array}$ \\
\hline $\begin{array}{l}\text { Likelihood } \\
\text { ratio test } \\
\text { for model }\end{array}$ & \multicolumn{2}{|c|}{$\chi 2=15.10 ; P=0.035$} & \multicolumn{2}{|c|}{$\chi 2=16.36 ; P=0.022$} & \multicolumn{2}{|c|}{$\chi 2=14.83 ; P=0.009$} \\
\hline${ }^{*} \mathrm{p}<0.05 ;{ }^{* *} \mathrm{p}$ & $.01 ; * \star * p<$ & Sample size & gression mc & 62 . & & \\
\hline
\end{tabular}




\section{Discussion}

We found that participants who received a video-assisted informed consent intervention showed greater knowledge of pediatric procedural sedation. Referring to the multimedia principle, a theory of multimedia learning, Mayer proposed that "people learn more deeply from words and pictures than from words alone."[31] Participants in the video intervention group showed greater satisfaction with the informed consent process than those in the conventional discussion control group. To our knowledge, this is the first study to use educational videos to improve the informed consent process for pediatric procedural sedation in the ED.

The informed consent process advocates the two core principles of patient well-being and patient autonomy,[14, 16] and physicians must respect and promote these principles. Informed consent comprises several essential components, including competence, disclosure, and voluntariness.[32, 33] A competent patient must receive adequate information from healthcare providers, understand the risks and benefits, and make decisions voluntarily based on his/her own values. In addition to the ethical aspects of informed consent, its legal requirements require physicians to provide information about medical procedures, risks and complications, benefits, and available alternatives.[14, 34]

Obtaining valid consent in the ED is a challenging and time-consuming process. It is often difficult for patients and their families to understand and absorb sufficient information to provide valid consent owing to time constraints, stress, and distress caused by acute symptoms or pain in the ED.[14-16, 18] Parents of children in the ED are generally considered the legal surrogates and decision makers. It is presumed that parents will make decisions according to the best interests of their child, maximizing benefits and minimizing possible risks and suffering.[35] Therefore, healthcare providers must work hard to convey the necessary information in an effective way to help patients and parents make effective decisions under demanding conditions.

Research on the decision-making framework for informed consent has identified many factors that affect patients' understanding of the process. Patient factors (e.g., age, education level, previous experience), physician factors (e.g., years in practice, communication skill, use of information aids), disease context (e.g., disease type, disease severity), and environmental factors (e.g., ordinary or emergency settings, time of visit) may affect information exchange, patient deliberation, and voluntarism regarding treatment decisions and consent.[36, 37] Our findings indicate that, after controlling for several factors, baseline knowledge scores and the use of the educational video influenced parents' knowledge and understanding. Future studies are needed to explore whether and how these factors affect the informed consent process in the ED for pediatric patients and their parents.

A previous study reported that parental educational level and sex of parent affect risk counseling recall; maternal parents showed better risk recall than paternal parents.[38] However, another study revealed that demographics were not related to parental recall rates during informed consent for emergency surgery for their children.[39] In our study, maternal parents and parents with education equal to or above college level in the intervention group showed a significantly greater difference in knowledge scores. Although the difference was not statistically significant in the multivariable analysis, sex of parent and education level seemed to have a greater impact on parental understanding after the video education. Future studies are needed to confirm these results.

The importance of the entire consent process should be emphasized: a good consent process may improve patient satisfaction and foster a good patient-physician relationship. Several strategies have been proposed to improve the consent process in the emergency setting. $[40,15]$ One study reported that using information aids may improve parental satisfaction with surgical informed consent in children.[41] Another study revealed that visual aids may improve communication about surgery between pediatric surgeons and surrogates.[42] During shared decision making, the physician may act as the parent's partner, providing information about diagnosis, treatment options, prognosis, and

Page $12 / 20$ 
possible risks and complications.[43] Physicians may communicate with parents about their perspectives and preferences, help them to discuss their values, and help them to make the best decisions for their children. A range of strategies have been used to improve patients' and parents' comprehension, including illustrative materials, leaflets and pamphlets, video descriptions, interactive computer programs,[3, 44-52] and "repeat back to me" or testing with feedback strategies.[53-55]

We found that baseline knowledge score and the use of an educational video were significant predictors of parental knowledge and understanding. Previous findings indicate that the use of video to educate adult patients and facilitate informed consent in the ED is effective.[44, 56-58] However, the effectiveness of preoperative education for pediatric patients and parents in the ED has not attracted much research interest. One study reported that standardized portable computer presentation was an effective way to improve education and facilitate the informed consent process in parents of children undergoing emergency surgery.[59] Traditionally, information about medical treatments or procedures is presented in written and/or verbal formats. However, research suggests that this standard approach often yields poor participant understanding of the information provided.[60] Possible reasons for poor understanding and memory retention include participants' lack of ability to read and understand material written above the suggested reading level, rushed and incomplete disclosure from information providers, use of unfamiliar medical terminology, and variability in the clarity and amount of information. One systematic review of informed consent in trauma patients reported that risk recall and comprehension were greater for written or video information than for only verbal information. Patients who received video information were more satisfied than patients who received written or verbal information.[40] The present results show that the video-assisted informed consent intervention resulted in improved understanding compared with the conventional informed consent discussion.

Recent advances in portable and tablet computer technology have provided good opportunities to improve parent preoperative education for pediatric emergency surgery.[15] The latest portable and tablet computers have larger screen displays, larger memory storage, and good image resolution, so can more easily deliver educational information and good quality videos. Consequently, the use of innovative portable computer technology may help to produce timely and effective preoperative education in the ED. In this study, we used a laptop with a preloaded video to educate parents and facilitate informed consent at the bedside in the ED. The results are promising, but additional studies are needed to further explore these findings.

We did not measure how much time was spent on the informed consent process for pediatric procedural sedation in both groups. Time spent on the informed consent process may affect participant comprehension and satisfaction.[38, 42 , 54] However, we believe that participants in both groups had sufficient time to obtain satisfactory information and similar opportunities to clarify their questions with their physicians to make medical decisions during the informed consent process. Therefore, it is unlikely that time affected the results.

It is essential that institutions establish an ethical environment for patient-centered healthcare.[61] One study recommended it is essential to define universal standards for informed consent.[62] We found that the video improved parental knowledge and satisfaction for the informed consent process in the ED. However, we believe that the main improvement was a result of the institution's efforts to improve patient safety and quality of care. The improvement in outcomes reflected these achievements. Institutions must both emphasize patient-centered healthcare as a top priority and attach importance to improved quality of care in the ED. ED staff need to share these values with other staff and healthcare personnel to provide appropriate care during all parts of the care process.

Furthermore, the importance of adequate education and training for healthcare providers to deliver structured and comprehensive information in a timely manner in the ED should not be underestimated. Effective communication of 
complicated information helps patients to understand the relevant information and make decisions. A good informed consent process can also promote good patient-physician relationships and build trust.

Our study had several limitations. First, this was one intervention for a particular population at one institution and thus the findings may not be generalizable to other situations or populations. Second, although the video-assisted informed consent intervention improved information understanding, it remains unclear how it influenced the decision to accept the procedure. No participants refused consent for the procedure after being informed by either the conventional process or the video. However, the choice of study design and population may have made it likely that participants were already aware of the procedure's necessity and had made an initial decision to accept it prior to recruitment. Further studies are needed to examine the effect of video-assisted informed consent intervention on decision making. Moreover, there are no reliable and valid measures of participant understanding of the benefits, risks, and alternatives of pediatric procedural sedation. In this study, the video and the knowledge test developed by a panel of experts demonstrated face validity and included information that we believed participants should know before providing consent for the procedure. The knowledge test focused on the purpose, risks, and benefits of the procedure and participants showed substantial improvement in their understanding of these aspects. However, knowledge about alternative treatments was not measured. It would have been useful to assess this and to determine whether the intervention improved participants' understanding of alternatives. Furthermore, we did not evaluate the effect of video education on parents' anxiety. A previous study reported that a multimedia intervention significantly reduced anxiety and increased knowledge in parents.[63] Further studies are needed to confirm these findings in the ED.

\section{Conclusions}

The use of a video-assisted informed consent intervention can improve the process of informed consent for pediatric procedural sedation in the ED. Video-assisted informed consent interventions may improve participant understanding of the procedure and satisfaction with the informed consent process. To confirm these initial findings, additional studies are needed of patients receiving different types of procedures or surgeries. Institutions should develop structured and standardized methods to better inform parents in the ED. Educational videos may be useful to improve communication between healthcare providers and patients and families, thereby further facilitating treatment decisions.

\section{Abbreviations}

Emergency department

ED

\section{Declarations}

\section{Ethics approval and consent to participate:}

The study protocol was reviewed by the institutional review board of Kaohsiung Medical University Hospital, Taiwan, before the study began. Participants in the control and intervention groups provided written informed consent before enrollment. The ClinicalTrials.gov Identifier is NCT01850329.

\section{Consent for publication:}

Not applicable. 


\section{Availability of data and material:}

The datasets obtained and/or analyzed during the current study are available from the corresponding author on reasonable request.

\section{Competing interests:}

The authors declare that they have no competing interests.

\section{Funding:}

This project was supported by grants from the Ministry of Science and Technology (MOST 107-2511-H-037 -004 -MY2) and Kaohsiung Medical University Hospital (KMUH108-8R33). This study is also supported partially by Kaohsiung Medical University Research Center Grant (KMU-TC108B10). The funders had no role in the design of the study and collection, analysis, and interpretation of data and in writing the manuscript.

\section{Authors' contributions:}

LYK and SL conceived and designed the study. CCW and LWC carried out the acquisition of data. LCJ performed the analysis and interpretation of data. LYK and LCJ drafted the manuscript. YYS and KLC participated in critical revisions. All authors read and approved the final manuscript.

\section{Acknowledgments:}

The authors are grateful for the help of the Statistical Analysis Laboratory, Department of Medical Research, Kaohsiung Medical University Hospital, Kaohsiung Medical University, Taiwan. We thank Diane Williams, PhD, from Edanz Group (www.edanzediting.com/ac) for editing a draft of this manuscript.

\section{References}

1. Beauchamp TL, Childress JF. Principles of Biomedical Ethics. Fifth edition ed. New York: Oxford University Press, Inc.; 2001.

2. Faden RR, Beauchamp TL, King NMP. A history and theory of informed consent. New York: Oxford University Press; 1986.

3. Farrell EH, Whistance RN, Phillips K, Morgan B, Savage K, Lewis V, et al. Systematic review and meta-analysis of audio-visual information aids for informed consent for invasive healthcare procedures in clinical practice. Patient Educ Couns. 2014;94(1):20-32. doi:10.1016/j.pec.2013.08.019.

4. Bernat JL, Peterson LM. Patient-centered informed consent in surgical practice. Arch Surg. 2006;141(1):86-92. doi:10.1001/archsurg.141.1.86.

5. Klove CA, DiBoise SJ, Pang B, Yarbrough WC. Informed consent: ethical and legal aspects. Thorac Surg Clin. 2005;15(2):213-9. doi:10.1016/j.thorsurg.2005.02.005.

6. Baum N. Informed consent-more than a form. The Journal of medical practice management: MPM. 2006;22(3):145-8.

7. Scarrow AM, Scarrow MR. Informed consent for the neurosurgeon. Surg Neurol. 2002;57(1):63-8. discussion 8-9. 
8. Grady C. Enduring and emerging challenges of informed consent. N Engl J Med. 2015;372(22):2172. doi:10.1056/NEJMc1503813.

9. Dickens BM, Cook RJ. Dimensions of informed consent to treatment. International journal of gynaecology and obstetrics: the official organ of the International Federation of Gynaecology and Obstetrics. 2004;85(3):309-14. doi:10.1016/j.ijgo.2004.03.001.

10. McGaughey I. Informed consent and knee arthroscopies: an evaluation of patient understanding and satisfaction. Knee. 2004;11(3):237-42. doi:10.1016/s0968-0160(03)00107-8.

11. Katsafourou PA, Gbolade BA. Informed consent for elective and emergency surgery: questionnaire study. BJOG. 2005;112(10):1454-5. doi:10.1111/j.1471-0528.2005.00669.x. author reply 5.

12. Woolf SH, Chan EC, Harris R, Sheridan SL, Braddock CH 3rd, Kaplan RM, et al. Promoting informed choice: transforming health care to dispense knowledge for decision making. Ann Intern Med. 2005;143(4):293-300.

13. Mishra PK, Ozalp F, Gardner RS, Arangannal A, Murday A. Informed consent in cardiac surgery: is it truly informed? Journal of cardiovascular medicine (Hagerstown Md). 2006;7(9):675-81. doi:10.2459/01.JCM.0000243001.59675.bf.

14. Moskop JC. Informed consent in the emergency department. Emerg Med Clin North Am. 1999;17(2):327-40. ix-x.

15. Nwomeh BC, Waller AL, Caniano DA, Kelleher KJ. Informed consent for emergency surgery in infants and children. J Pediatr Surg. 2005;40(8):1320-5. doi:10.1016/j.jpedsurg.2005.05.019.

16. Moskop JC. Informed consent and refusal of treatment: challenges for emergency physicians. Emerg Med Clin North Am. 2006;24(3):605-18. doi:10.1016/j.emc.2006.05.009.

17. Consent for emergency. medical services for children and adolescents. Pediatrics. 2003;111(3):703-6.

18. Thewes J, FitzGerald D, Sulmasy DP. Informed consent in emergency medicine: ethics under fire. Emerg Med Clin North Am. 1996;14(1):245-54.

19. Krauss B, Green SM. Procedural sedation and analgesia in children. The Lancet. 2006;367(9512):766-80.

20. Bahn EL, Holt KR. Procedural sedation and analgesia: a review and new concepts. Emerg Med Clin North Am. 2005;23(2):503-17. doi:10.1016/j.emc.2004.12.013.

21. Melendez E, Bachur R. Serious Adverse Events During Procedural Sedation With Ketamine. [Article]. Pediatr Emer Care:. 2009;25:325-8.

22. Green SM, Kuppermann N, Rothrock SG, Hummel CB, Ho M. Predictors of adverse events with intramuscular ketamine sedation in children. Ann Emerg Med. 2000;35(1):35-42.

23. Green SM, Krauss B. Clinical practice guideline for emergency department ketamine dissociative sedation in children. Ann Emerg Med. 2004;44(5):460-71. doi:10.1016/s0196064404006365.

24. Green SM, Roback MG, Krauss B, Brown L, McGlone RG, Agrawal D, et al. Predictors of emesis and recovery agitation with emergency department ketamine sedation: an individual-patient data meta-analysis of 8,282 children. Ann Emerg Med. 2009;54(2):171 - 80. e1-4. doi:10.1016/j.annemergmed.2009.04.004.

25. Green SM, Roback MG, Kennedy RM, Krauss B. Clinical practice guideline for emergency department ketamine dissociative sedation: 2011 update. Ann Emerg Med. 2011;57(5):449-61.

doi:10.1016/j.annemergmed.2010.11.030.

26. Zvara DA, Mathes DD, Brooker RF, McKinley AC. Video as a patient teaching tool: does it add to the preoperative anesthetic visit? Anesth Analg. 1996;82(5):1065-8.

27. Snyder-Ramos SA, Seintsch H, Bottiger BW, Motsch J, Martin E, Bauer M. Patient Satisfaction and Information Gain After the Preanesthetic Visit: A Comparison of Face-to-Face Interview, Brochure, and Video. Anesth Analg.

2005;100(6):1753-8. doi:10.1213/01.ane.0000153010.49776.e5.

Page $16 / 20$ 
28. Salzwedel C, Petersen C, Blanc I, Koch U, Goetz AE, Schuster M. The effect of detailed, video-assisted anesthesia risk education on patient anxiety and the duration of the preanesthetic interview: a randomized controlled trial. Anesth Analg. 2008;106(1):202-9. doi:10.1213/01.ane.0000287665.96156.72. table of contents.

29. Lee A, Chui PT, Gin T. Educating Patients About Anesthesia: A Systematic Review of Randomized Controlled Trials of Media-Based Interventions. Anesth Analg. 2003;96(5):1424-31.

30. Steffenino G, Viada E, Marengo B, Canale R. Effectiveness of video-based patient information before percutaneous cardiac interventions. Journal of cardiovascular medicine (Hagerstown Md). 2007;8(5):348-53. doi:10.2459/01.Jcm.0000268131.64598.49.

31. Mayer RE. Multimedia learning. 2nd ed. New York:: Cambridge University Press; 2009.

32. Bunch WH. Informed consent. Clin Orthop Relat Res. 2000(378):71-7.

33. Etchells E, Sharpe G, Dykeman MJ, Meslin EM, Singer PA. Bioethics for clinicians:4. Voluntariness. Can Med Assoc J. 1996;155(8):1083-6.

34. Kondziolka DS, Pirris SM, Lunsford LD. Improving the informed consent process for surgery. Neurosurgery. 2006;58(6):1184-9. discussion - 9.

35. Dreisinger N, Zapolsky N. Complexities of Consent: Ethics in the Pediatric Emergency Department. Pediatr Emerg Care. 2018;34(4):288-90. doi:10.1097/pec.0000000000001131.

36. Leon-Carlyle M, Spiegle G, Schmocker S, Gagliardi A, Urbach D, Kennedy E. Using patient and physician perspectives to develop a shared decision-making framework for colorectal cancer. Implementation science: IS. 2009;4:81. doi:10.1186/1748-5908-4-81.

37. Agu KA, Obi El, Eze Bl, Okenwa WO. Attitude towards informed consent practice in a developing country: a community-based assessment of the role of educational status. BMC Med Ethics. 2014;15:77. doi:10.1186/14726939-15-77.

38. Nadeau DP, Rich JN, Brietzke SE. Informed consent in pediatric surgery: Do parents understand the risks? Arch Otolaryngol Head Neck Surg. 2010;136(3):265-9. doi:10.1001/archoto.2010.5.

39. Li FX, Nah SA, Low Y. Informed consent for emergency surgery-how much do parents truly remember? J Pediatr Surg. 2014;49(5):795-7. doi:10.1016/j.jpedsurg.2014.02.075.

40. Lin YK, Liu KT, Chen CW, Lee WC, Lin CJ, Shi L, et al. How to effectively obtain informed consent in trauma patients: a systematic review. BMC Med Ethics. 2019;20(1):8. doi:10.1186/s12910-019-0347-0.

41. Chotai PN, Nollan R, Huang EY, Gosain A. Surgical informed consent in children: a systematic review. J Surg Res. 2017;213:191-8. doi:10.1016/j.jss.2017.02.047.

42. Lashley M, Talley W, Lands LC, Keyserlingk EW. Informed proxy consent: communication between pediatric surgeons and surrogates about surgery. Pediatrics. 2000;105(3 Pt 1):591-7.

43. Kunneman M, Montori VM. When patient-centred care is worth doing well: informed consent or shared decisionmaking. BMJ Qual Saf. 2017;26(7):522-4. doi:10.1136/bmjqs-2016-005969.

44. 10.1016/j.annemergmed.2006.07.934

Cowan EA, Calderon Y, Gennis P, Macklin R, Ortiz C, Wall SP. Spanish and English video-assisted informed consent for intravenous contrast administration in the emergency department: a randomized controlled trial. Ann Emerg Med. 2007;49(2):221 - 30, 30.e1-3. doi:10.1016/j.annemergmed.2006.07.934.

45. Eaden J, Abrams K, Shears J, Mayberry J. Randomized controlled trial comparing the efficacy of a video and information leaflet versus information leaflet alone on patient knowledge about surveillance and cancer risk in ulcerative colitis. Inflamm Bowel Dis. 2002;8(6):407-12. 
46. Rossi MJ, Guttmann D, MacLennan MJ, Lubowitz JH. Video informed consent improves knee arthroscopy patient comprehension. Arthroscopy. 2005;21(6):739-43. doi:10.1016/j.arthro.2005.02.015.

47. Tait AR, Voepel-Lewis T, Moscucci M, Brennan-Martinez CM, Levine R. Patient Comprehension of an Interactive, Computer-Based Information Program for Cardiac Catheterization: A Comparison With Standard Information. Arch Intern Med. 2009;169(20):1907-14. doi:10.1001/archinternmed.2009.390.

48. Bollschweiler E, Apitzsch J, Obliers R, Koerfer A, Monig SP, Metzger R, et al. Improving informed consent of surgical patients using a multimedia-based program? Results of a prospective randomized multicenter study of patients before cholecystectomy. Ann Surg. 2008;248(2):205-11. doi:10.1097/SLA.0b013e318180a3a7.

49. Pallett AC, Nguyen B, Klein NM, Phippen N, Miller CR, Barnett JC. A randomized controlled trial to determine whether a video presentation improves informed consent for hysterectomy. Am J Obstet Gynecol. 2018. doi:10.1016/j.ajog.2018.06.016.

50. Villanueva C, Talwar A, Doyle M. Improving informed consent in cardiac surgery by enhancing preoperative education. Patient Educ Couns. 2018;101(12):2047-53. doi:10.1016/j.pec.2018.06.008.

51. Lattuca B, Barber-Chamoux N, Alos B, Sfaxi A, Mulliez A, Miton N, et al. Impact of video on the understanding and satisfaction of patients receiving informed consent before elective inpatient coronary angiography: A randomized trial. Am Heart J. 2018;200:67-74. doi:10.1016/j.ahj.2018.03.006.

52. Ashraff S, Malawa G, Dolan T, Khanduja V. Prospective randomised controlled trial on the role of patient information leaflets in obtaining informed consent. ANZ J Surg. 2006;76(3):139-41. doi:10.1111/j.14452197.2006.03671.x.

53. Prochazka AV, Fink AS, Bartenfeld D, Henderson WG, Nyirenda C, Webb A, et al. Patient perceptions of surgical informed consent: is repeat back helpful or harmful? Journal of patient safety. 2014;10(3):140-5. doi:10.1097/PTS.0b013e3182a00317.

54. Fink AS, Prochazka AV, Henderson WG, Bartenfeld D, Nyirenda C, Webb A, et al. Predictors of comprehension during surgical informed consent. J Am Coll Surg. 2010;210(6):919-26. doi:10.1016/j.jamcollsurg.2010.02.049.

55. Roberts KJ, Revenson TA, Urken ML, Fleszar S, Cipollina R, Rowe ME, et al. Testing with feedback improves recall of information in informed consent: A proof of concept study. Patient Educ Couns. 2016;99(8):1377-81. doi:10.1016/j.pec.2016.03.014.

56. Chan YF, Lavery R, Fox N, Kwon R, Zinzuwadia S, Massone R, et al. Effect of an educational video on emergency department patient stroke knowledge. J Emerg Med. 2008;34(2):215-20. doi:10.1016/j.jemermed.2007.04.003.

57. Lin YK, Chen CW, Lee WC, Cheng YC, Lin TY, Lin CJ, et al. Educational video-assisted versus conventional informed consent for trauma-related debridement surgery: a parallel group randomized controlled trial. BMC Med Ethics. 2018;19(1):23. doi:10.1186/s12910-018-0264-7.

58. Lin YK, Chen CW, Lee WC, Lin TY, Kuo LC, Lin CJ, et al. Development and pilot testing of an informed consent video for patients with limb trauma prior to debridement surgery using a modified Delphi technique. BMC Med Ethics. 2017;18(1):67. doi:10.1186/s12910-017-0228-3.

59. Nwomeh BC, Hayes J, Caniano DA, Upperman JS, Kelleher KJ. A parental educational intervention to facilitate informed consent for emergency operations in children. J Surg Res. 2009;152(2):258-63.

doi:10.1016/j.jss.2008.01.008.

60. Tait AR, Voepel-Lewis T, Malviya S, Philipson SJ. Improving the readability and processability of a pediatric informed consent document: effects on parents' understanding. Arch Pediatr Adolesc Med. 2005;159(4):347-52. doi:10.1001/archpedi.159.4.347.

61. Lin YK, Lee WC, Kuo LC, Cheng YC, Lin CJ, Lin HL, et al. Building an ethical environment improves patient privacy and satisfaction in the crowded emergency department: a quasi-experimental study. BMC Med Ethics. 2013;14:8.

Page $18 / 20$ 
doi:10.1186/1472-6939-14-8.

62. Shahu A, Schwartz J, Perez M, Bernheim SM, Krumholz HM, Spatz ES. Discerning quality: an analysis of informed consent documents for common cardiovascular procedures. BMJ Qual Saf. 2017;26(7):569-71. doi:10.1136/bmjqs-2016-005663.

63. Paton EA, Davis SK, Gaylord N, Cao X, Gosain A. Impact of a multimedia teaching tool on parental anxiety and knowledge during the informed consent process. Pediatr Surg Int. 2018;34(12):1345-52. doi:10.1007/s00383-0184352-z.

\section{Figures}

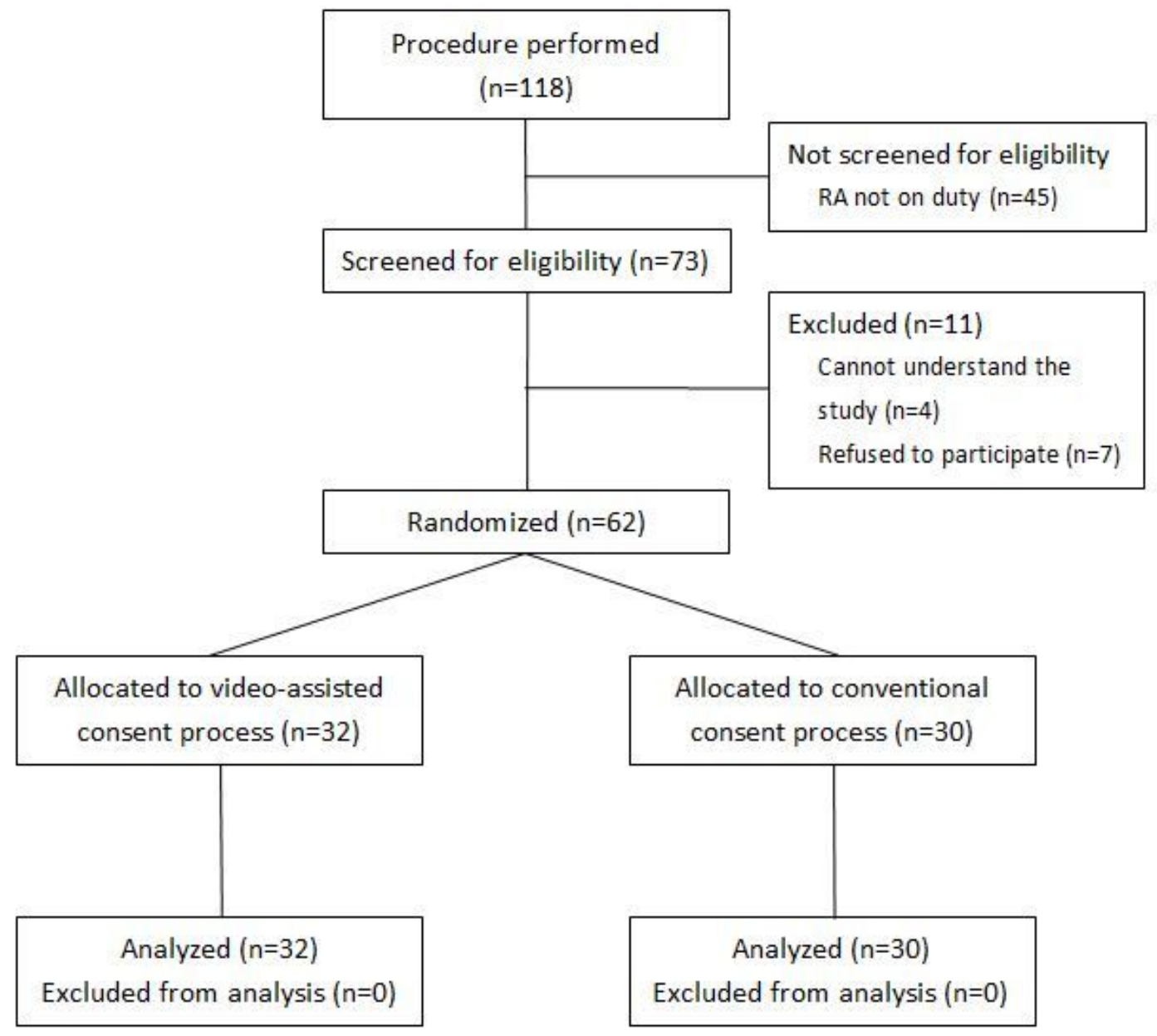

\section{Figure 1}

Profile of randomized controlled trial. (RA, Research associate.)

\section{Supplementary Files}

This is a list of supplementary files associated with this preprint. Click to download.

- BMCMEappendix6CONSORT2010Checklist20200506.doc

- BMCMEappendix1pediatricsedation20200501.docx 
- BMCMEappendix4pediatricsedation20200501.docx

- BMCMEappendix3pediatricsedation20200501.docx

- BMCMEappendix5pediatricsedation20200501.docx

- BMCMEappendix2pediatricsedation20200501.docx 